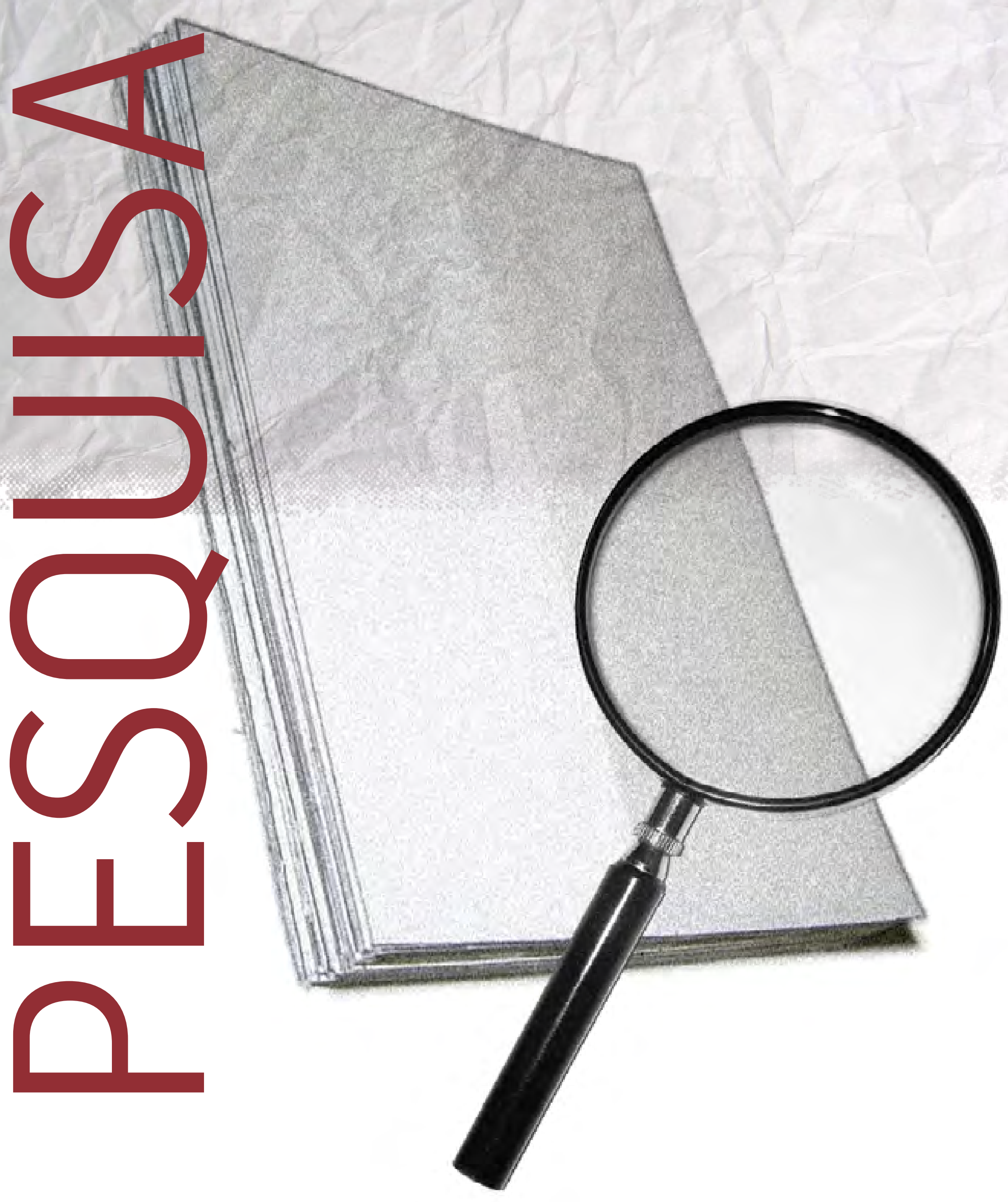




\section{A interculturalidade no ensino-aprendizagem em relações públicas: contribuições a partir de uma parceria internacional'}

Interculturalism in the teaching-apprenticeship process in public relations: contributions from an international partnership

La interculturalidad en la enseñanza-aprendizaje en relaciones públicas: contribuciones a partir de un acuerdo internacional

Célia Maria Retz Godoy dos Santos

Doutora em Sociologia - Unesp-Araraquara

- E-mail: celiaretz@faac.unesp.br

Maria Eugênia Porém

Doutora em Educação Escolar - Unesp-Araraquara

- E-mail:meporem@faac.unesp.br

(9) Raquel Cabral

- Doutora em Comunicação Institucional - Universitat Jaume I, Espanha

- E-mail: raquelc@faac.unesp.br

9. Tamara de Souza Brandão Guaraldo

- Doutora em Ciência da Informação - Unesp-Marilia

- E-mail: tamara@faac.unesp.br

(9) Roseane Andrelo

- Doutora em Educação Escolar - Unesp-Araraquara

- E-mail: roseane.andrelo@faac.unesp.br

(9) Angélica Aparecida Parreira Lemos Ruiz

- Bacharel em Psicologia - Unesp-Bauru

- E-mail: angélica@faac.unesp.br 


\section{Resumo}

Este trabalho apresenta aspectos de uma experiência intercultural referente à parceria internacional de ensinoaprendizagem em relações públicas entre a Universidade Estadual Paulista (Brasil) e a Universidade de Sevilha (Espanha). 0 objetivo é refletir sobre a noção de interculturalidade e sua importância na formação em relações públicas, apresentando resultados dessa intervenção acadêmica. Para tanto, buscamos descrever a parceria, discutir as influências desse processo de ensino-aprendizagem e sua vivência intercultural.

\section{PALAVRAS CHAVE: RELAÇÕES PÚBLICAS • INTERCULTURALIDADE・ENSINO-APRENDIZAGEM.}

\section{Abstract}

This paper presents the aspects of an intercultural experience relative to the international partnership of teachingapprenticeship in public relations between the São Paulo State University (Brazil) and the University of Sevilla (Spain). The purpose is of reflecting on the interculturality and its importance for the graduation in public relations, presenting results of this academic experience. To this end, we seek to describe the partnership, discuss the influences of this teachingapprenticeship process and its intercultural experience.

\section{KEYWORDS: PUBLIC RELATIONS •INTERCULTURALITY・TEACHING-APPRENTICESHIP PROCESS.}

\section{Resumen}

Este trabajo presenta aspectos de una experiencia intercultural en relación al acuerdo internacional de enseñanzaaprendizaje en relaciones públicas entre la Universidad Estadual Paulista (Brasil) y la Universidad de Sevilla (España). El objetivo es reflexionar sobre la noción de interculturalidad y su importancia en la formación en relaciones públicas, presentando resultados de esa experiencia académica. Para eso, buscamos describir el acuerdo, discutir las influencias de ese proceso de enseñanza-aprendizaje y su vivencia intercultural. 
A questão central deste artigo é a mediação intercultural na implantação de uma parceria internacional de ensinoaprendizagem em relações públicas. Assim, se discute, para além do valor intrínseco que fundamenta as relações públicas como comprometidas com o estabelecimento do diálogo e dos relacionamentos com os públicos, a interculturalidade na formação dos futuros profissionais. De modo específico, relata-se o início de uma parceria entre uma universidade do Brasil e outra da Espanha) trazendo colaborações, comprometimentos, interesses e dificuldades comunicacionais oriundas dessa interação.

A pesquisa participante é a metodologia utilizada, pois os pesquisadores são parte do evento analisado e atuam em sua implantação e em atividades, vivenciando a experiência que é objeto desta análise. Esse tipo de pesquisa "pode ter a finalidade de observar os processos comunicativos interpessoais, grupais ou comunitários (...) e se originar do interesse do investigador ou de um grupo que objetiva conhecer melhor seus processos de comunicação" (Peruzzo, 2005, p. 136-7).

Nesse sentido, no primeiro item do artigo, são discutidos o conceito de interculturalidade, as exigências em relação ao diálogo intercultural nas organizações e a necessidade de formar o relações-públicas para atuar em um cenário marcado pela integração de culturas. Posteriormente, é apresentada a parceria entre as universidades, objeto desta análise, e, por fim, mediante a fundamentação teórica e a descrição da experiência, discute-se a formação em relações públicas a partir de um olhar intercultural.

\section{COMPETÊNCIAS INTERCULTURAIS NO ÂMBITO DAS RELAÇÕES PÚBLICAS}

Em tempos de globalização econômica e mundialização da cultura, nunca foi tão importante a formação intercultural para os indivíduos e as organizações. Nesse contexto, entendendo o profissional de relações públicas como gestor de relacionamentos, esta competência é potencialmente indispensável.

Por outro lado, pensar em integração de culturas também significa desenvolver temas que discutam a internacionalização do conhecimento, o que exige reflexão aprofundada sobre a noção de interculturalidade no processo atual de ensino-aprendizagem, especialmente no âmbito da formação dos relações-públicas. O fenômeno da globalização coloca em evidência a necessidade da análise de como as culturas se relacionam umas com as outras e, simultaneamente, da consciência em relação aos valores que partilham. Nesse sentido, segundo o Relatório Mundial sobre a Diversidade Cultural publicado pela Unesco, em 2009, essa interrelação e interdependência entre culturas estão levando nossas sociedades ao desenvolvimento de um diálogo intercultural, necessário para a convivência em um mundo diverso, no qual as interações culturais se tornam cada vez mais frequentes.

Cabe, portanto, discutir sobre a própria noção de interculturalidade, já que o termo abrange diversas perspectivas conceituais e posicionamentos teóricos distintos. Para Catherine Walsh (2005, p. 10-11), a interculturalidade é

um processo dinâmico e permanente de relação, comunicação e aprendizagem entre culturas em condições de respeito, legitimidade mútua, simetria e igualdade. Um intercâmbio que se constrói entre pessoas, conhecimentos, saberes e práticas culturalmente diferentes, buscando desenvolver um novo sentido entre elas na sua diferença. Um espaço de negociação e de tradução onde as desigualdades sociais, econômicas e políticas e as relações e os conflitos de poder da sociedade não são mantidos ocultos e sim reconhecidos e confrontados. Uma tarefa social e política que interpela o conjunto da sociedade, que parte de práticas e ações sociais concretas e conscientes e tenta criar modos de responsabilidade e solidariedade. 
Assim, ao refletir sobre interculturalidade, Ana Maria D'Ávila Lopes (2012, p. 69) explica que é fundamental diferenciála de multiculturalismo.

Enquanto o multiculturalismo propugna a coexistência num mesmo espaço social de culturas diferentes sob o princípio da tolerância e do respeito à diferença, a interculturalidade, ao pressupor como inevitável a interação entre essas culturas, propõe um projeto político capaz de estabelecer um diálogo entre elas, como forma de garantir uma real convivência pacífica.

Como se observa, a interculturalidade pressupõe uma efetiva integração, na qual a negociação e o diálogo pautam a dinâmica de interação cultural. Nesse sentido, Alvarado (2003, apud LOPES, 2012, p. 69) aponta as principais características em relação ao conceito de interculturalidade:

a) é um conceito dinâmico que supera o multiculturalismo ao reconhecer a sociedade como um espaço de permanente interação; b) propugna não apenas o respeito à diversidade cultural, mas a necessidade da convivência e troca de experiências; c) procura recriar as culturas existentes, reconhecendo que se encontram em permanente transformação; d) propõe uma nova síntese cultural, o que implica a reelaboração dos modelos culturais preconcebidos; e) pressupõe a interação entre as culturas que, embora muitas vezes tensa, pode ser regulada.

Pode-se dizer que a interculturalidade propicia condições ideais para que novos olhares possam transformar a realidade. Raúl Fornet-Betancourt (2006, p. 29) reafirma a ideia de que a "interculturalidad supone diversidad y diferencia, diálogo y contraste, que suponen a su vez procesos de apertura, de indefinición e incluso de contradicción".

Um dos desafios a se enfrentar na promoção de uma educação intercultural, numa perspectiva crítica e emancipatória que permite a articulação das diferenças e promove os direitos humanos (Candau; Moreira, 2003), é minimizar a tensão, presente hoje no debate público e nas relações internacionais, entre igualdade e diferença.

Segundo Boaventura de Souza Santos (2006), este desafio se concentra em torno de núcleos fundamentais como:

1) A necessidade de desconstrução, pois numa educação intercultural urge promover a desnaturalização da rede de estereótipos e pré-conceitos existentes nos imaginários individuais e sociais e também daqueles presentes nas politicas educativas e nos currículos vigentes;

2) A articulação entre igualdade e diferença das políticas educativas e práticas pedagógicas, as quais envolvem 0 reconhecimento e a valorização das diferenças culturais dos diversos saberes e práticas, garantindo aos sujeitos a interseção sociocultural que rompe com o caráter monocultural;

3) 0 resgate dos processos de construção das identidades culturais, tanto no âmbito pessoal como no coletivo, com especial atenção à história de vida dos envolvidos e aos aspectos relativos à hibridização cultural para a constituição de novas identidades culturais;

4) A promoção de experiências de interação sistemática com os "outros" a fim de sermos capazes de relativizar a própria maneira de situar-nos diante do mundo, rompendo com a tendência a "gueto"; 
5) O favorecimento dos processos de "empoderamento", especialmente aos atores sociais historicamente com menores possibilidades de influir nas decisões e nos processos coletivos.

Especificamente no campo das organizações, vê-se que são várias as definições sobre cultura, as quais incorporam a dimensão de poder como agente de legitimação e a ideologia vivenciada pelos seus membros. Para Maria Aparecida Ferrari (2009, p. 185), a "cultura nacional deixa marcas na sociedade e no mundo dos negócios", mas também os relacionamentos transculturais influenciam na cultura organizacional. Por isso, seja observando a rotina das organizações ou definindo os impactos das diferentes culturas sobre ela, cabe ao relações-públicas conhecê-las com vistas a otimizar os processos de relacionamento entre os públicos por meio da comunicação. Daí a influência dos relacionamentos interculturais, "tanto na prática das relações públicas, como no papel desempenhado por este profissional" junto às organizações (Ferrari, 2009, p. 185).

Chama a atenção o fato de que a interculturalidade pressupõe a troca de experiências entre indivíduos com culturas diversas, que por vezes ultrapassa a dimensão linear da socialização de informações numa determinada organização. 0 ambiente social entre os interlocutores varia de cultura para cultura e adquire significados distintos. Essa variação na produção de significado não é característica única de culturas distintas. Conforme conjectura Cristina Peñamarín (2006), no universo da cultura linguística de nativos, também há lugar para o mal-entendido. A autora destaca o fato de que comunicar nem sempre é sinônimo de compreender-se plenamente.

Sin contradicción podemos sostener simultáneamente que el diálog y y la inter-traducción siempre son posibles entre cualesquiera culturas, y que, sin embargo, con frecuencia no es posible la comprensión mutua entre dos interlocutores. La incomprensión no es un obstáculo epistemológico para la semiótica de la comunicación, donde hemos sostenido desde hace tiempo que el malentendido es estructural en la comunicación, y hemos observado el fenómeno desde este punto de partida, en lugar de suponer que comunicar es sinónimo de comprenderse plenamente. También entendemos que cada encuentro comunicativo debe considerarse un encuentro intercultural, pues la significación ocurre siempre en textos y procesos que activan múltiples códigos y sistemas de significación, ya que implican las varias culturas de emisor y receptor (Peñamarín, 2006, p. 141-142).

0 tom e as inflexões de voz numa conversa, a maneira de pronunciar as palavras, a escolha dos termos, os movimentos do corpo e a interrupção do interlocutor são alguns exemplos de competências reveladoras da capacidade comunicativa que deve ser apropriada pelas relações públicas.

Por isso, pondera-se que a interculturalidade deva ser um dos aspectos trabalhados nos currículos escolares de formação superior em relações públicas, uma vez que é intrínseca ao profissional dessa área a capacidade de legitimar o diálogo com diversos públicos, agora globais. A diversidade de culturas com que os futuros profissionais estarão sujeitos a dialogar faz emergir a necessidade de uma formação que compreenda as culturas e suas subjetividades, os modos de pensar e agir de cada sociedade e como tudo isso interfere no relacionamento entre organizações e seus públicos.

Não por acaso, muitas instituições de ensino superior buscam formar parcerias internacionais de modo que possam, a partir de uma experiência entre culturas distintas, fazer emergir a aprendizagem intercultural, do olhar para o outro e do aprender com ele, para formar profissionais cidadãos do mundo, aptos a trabalhar em mercados globais e, ao mesmo tempo, conscientes de seu papel como cidadãos. 


\section{A PARCERIA INTERCULTURAL ENTRE A UNIVERSIDADE ESTADUAL PAULISTA E A UNIVERSIDADE DE SEVILHA}

Desde1995aUniversidadedeSevilhadesenvolveummodelodeensino-aprendizagemnoCursodePublicidadeeRelaçõesPúblicas, a partir de situações reais do mercado de trabalho profissional dessas áreas, envolvendo produção coletiva de conhecimento, trabalho em equipes de alta performance, gestão do relacionamento, postura profissional, estratégia e criatividade.

Em linhas gerais, esse modelo de ensino-aprendizagem parte de uma situação problemática real de mercado, em que é apresentado um cliente a grupos de estudantes que se tornam agências de comunicação. Estas, de forma competitiva e ao mesmo tempo colaborativa, têm como objetivo desenvolver uma campanha de comunicação para atender às demandas solicitadas pelo cliente. Para o estudante, essa experiência se constitui numa oportunidade singular a partir do momento em que se estabelece uma interação efetiva mediante um briefing real.

Partindo dessa proposta e pensando no impacto que o fenômeno da globalização produz na dinâmica do mercado atual, em 2014 esse modelo de ensino-aprendizagem espanhol é ampliado para uma versão internacional mediante um acordo de cooperação entre a Universidade Estadual Paulista (Unesp) e a Universidade de Sevilha. Nessa nova configuração, a parceria assume um forte componente intercultural a partir do momento em que se compreende a fundamental importância da interação entre culturas na conformação de estratégias internacionais de comunicação. Nesse contexto, surgem desafios que buscam contrapor as demandas do mercado global com as novas diretrizes das instituições de ensino superior do mundo todo, as quais visam à internacionalização do ensino-aprendizagem e da pesquisa em relações públicas.

Na Espanha, mais especificamente em Sevilha, o ensino de relações públicas está articulado com a área de publicidade e propaganda, modelo adotado em boa parte da Europa. Tem-se como resultado uma formação voltada ao contexto mercadológico e sociocultural de inserção profissional naqueles países, nos quais as relações públicas se articulam-se à publicidade. No Brasil, os dois cursos são oferecidos separadamente, o que pressupõe uma diferenciação entre as áreas, conhecimentos, legislação e reconhecimento profissional. 0 curso de graduação em relações públicas, especialmente na Unesp, ao atender às diretrizes curriculares nacionais da profissão, reconhece igualmente a importância de uma visão e identidade brasileira e latino-americana, na qual se privilegiam conhecimentos teóricos e habilidades técnicas com um forte conteúdo humanístico.

É importante ressaltar que, apesar das diferenças nas concepções político- pedagógicas do curso de relações públicas na Espanha e no Brasil, especialmente na formação técnica, também encontramos convergências em termos de conteúdos teóricos que fundamentam a profissão. É o caso de disciplinas de marketing, publicidade no terceiro setor, economia, teorias da comunicação, imagem e comunicação corporativa, teorias e técnicas de relações públicas, que, embora assumam nomenclaturas distintas, possuem similaridades de conteúdos.

No que diz respeito à iniciativa mencionada, da criação de agências de comunicação para atendimento a um cliente real, cabe ressaltar que ela representa o elo entre as disciplinas do currículo, fazendo com que os alunos articulem, na prática e no tempo do mercado, os diversos conteúdos trabalhados no curso. Mais do que isso, a partir da cooperação assinada entre as universidades dos dois países, é necessária uma gestão do processo que considere as duas culturas, espanhola e brasileira. 
Ao transpor os muros da universidade, o modelo de ensino-aprendizagem, necessariamente, envolve a interação com públicos distintos: alunos, professores, cliente, patrocinadores, associações de classe, mídia e comunidade. A partir do momento em que se somam essas mesmas categorias de público de dois países, acrescentam-se desafios: como manter a identidade da proposta e, ao mesmo tempo, respeitar as diferenças culturais dos públicos envolvidos? Como, apesar dos avanços tecnológicos, fazer com que realmente haja integração entre docentes e discentes, permitindo o diálogo intercultural e, consequentemente, a formação para atuar em cenários interculturais?

Essas duas questões têm feito parte da concepção e gestão da parceria que se encontra em fase inicial. Até o momento, foram estabelecidas as diretrizes do modelo de ensino-aprendizagem, fizeram-se adaptações na metodologia e elaboraram-se instrumentos de comunicação dirigida aos stakeholders. Os atos comunicativos, foco desta análise, aconteceram de forma interpessoal presencial (com visitas nos dois países por professores e alunos) e mediada por tecnologias (com reuniões via skype), além do uso de mídias sociais.

Iniciativas como essa representam não apenas uma oportunidade legítima de aproximação do estudante de graduação a situações reais da dinâmica profissional, mas também alinham um dos objetivos de nossas universidades que se conduz em torno da internacionalização do ensino, da pesquisa e da extensão. De fato, a mencionada iniciativa reconhece a importância do debate intercultural para a sensibilização e compreensão dos conflitos organizacionais atuais, que já não conhecem fronteiras e requerem uma gestão integrada de talentos, visão estratégica e criatividade.

\section{CONTRIBUIÇÕES PARA O ENSINO-APRENDIZAGEM EM RELAÇÕES PÚBLICAS E O DESAFIO DE UMA PARCERIA INTERCULTURAL}

As situações que exigem que os indivíduos se comuniquem para estabelecer relacionamentos, definir estruturas ou explorar um campo de conhecimento são inúmeras e comportam vários traços característicos, impactando fortemente a parceria intercultural desenvolvida pelas universidades e, por que não dizer?, a sua identidade internacional.

Desse modo, à luz do referencial teórico e a partir da aplicação da metodologia de pesquisa participante, a qual exige "o compartilhamento, pelo investigador, das atividades do grupo ou do contexto que está sendo estudado, de modo consistente e sistematizado - ou seja, ele se envolve nas atividades, além de covivenciar interesses e fatos" (Peruzzo, 2005, p.126), busca-se traçar contribuições para a formação em relações públicas. A observação participante diz respeito às experiências, a tornarse parte da vida social, estabelecer e manter relacionamentos, com a teoria mediando as interpretações e categorização dos dados (May, 2004). Portanto, com base na realização dessa intervenção e conforme referencial teórico estudado, definiram-se quatro fatores para interpretação dessa parceria em relação à interculturalidade, a fim de englobar de forma significativa as transformações concretas: 1.Temporalidade; 2. Características dos participantes e o diálogo intercultural; 3 . Aspectos culturais; 4. Identidade das relações públicas.

Em relação ao primeiro fator, ao analisar a temporalidade entre as duas universidades, reconhecemos que ambas estão marcadas por atributos particulares, no que se refere às diferenças de fuso horário, calendário escolar em dias e períodos distintos, o gozo das férias e recessos acadêmicos, além da própria noção de tempo das duas culturas que desafia a dinâmica 
da integração dos grupos de docentes e estudantes. Não se trata de discutir o tempo cronológico, ditado pelo relógio, mas em compreender as concepções político-ideológicas que sinalizam o presente, o passado e o futuro com trajetórias históricas distintas. Nesses diferentes processos históricos, a noção de tempo imprime em cada cultura uma forma de ver e entender os acontecimentos e, ao mesmo tempo, de trabalhar com as variáveis do futuro, um aspecto extremamente estratégico no ensino-aprendizagem em relações públicas.

Contudo, cabe reconhecer que esse processo está sendo desenvolvido à medida que a integração intercultural se consolida. A compreensão de estruturas de significados distintos para ambas as culturas em relação ao tempo, nos leva a buscar aproximações efetivas mediante o estudo e o conhecimento das práticas culturais diárias das mesmas. Por exemplo, o curso tem início e término distintos em ambos os países. Assim, respeitando-se os calendários escolares, as reuniões via skype es atendimentos aos alunos são programados adaptando-se ao fuso horário e ao período letivo.

Já em relação ao segundo fator, características dos participantes e diálogo intercultural, observam-se as singularidades entre os dois cursos, nos quais alguns elementos teóricos e metodológicos entram em negociação. No momento em que se identificam convergências ou divergências importantes, se estabelece um cenário de diálogo intercultural para o tratamento dessas particularidades que afetam o processo. Nem sempre a presença de divergências pode ser algo negativo, tanto em relação a conteúdos teóricos ou técnicos como em relação às características culturais que nos fazem distintos. Por essa razão, entende-se que, mesmo diante de todos esses atributos distintos, elas nos levam a convergir a objetivos e desafios comuns.

A língua e a necessidade de interlocutores qualificados, que participam das decisões, negociações e discussões formais e informais entre os parceiros, se destacam como elementos essenciais que nos levam a discutir e refletir sobre a característica intercultural dessa parceria e nos oferecem oportunidades ímpares para pensar a diversidade de olhares e perspectivas do processo comunicacional. Exemplificando esse fator, tem-se o caso da hashtag \#candelallama, utilizada como palavra-chave para designar as atividades realizadas em tempo real, na internet, pelo programa na Espanha. No caso brasileiro, o uso da mesma hashtagnão produziria o mesmo efeito, já que o sentido não corresponde ao espanhol no contexto da cultura linguística brasileira. Após esta observação, sugeriu-se a proposta de \#aluzdomundo para ambos os programas no Brasil e na Espanha, 0 que também não foi possível, visto que essa expressão produz conotação mística no contexto brasileiro. Entendeu-se, então, não se tratar apenas de uma tradução ou adaptação, mas da busca na própria cultura linguística e no repertório cultural dos participantes de um termo que produzisse o sentido conceitual similar em ambas as universidades. Para isso, percebeu-se a necessidade de maior vivência intercultural e partilha de significados durante a referida experiência acadêmica, a fim de que, a partir dela, a produção de sentidos se estabelecesse de maneira legítima.

Em relação ao terceiro fator, aspectos culturais, entendemos que ele está presente de forma transversal. Primeiro, em relação à cultura linguística, cabe refletir sobre o papel fundamental da língua como meio de transmissão de cultura e concepções de mundo, conforme aponta a Unesco (2009, p. 12):

As línguas são os vetores das nossas experiências, dos nossos contextos intelectuais e culturais, dos nossos modos de relacionamento com os grupos humanos, com os nossos sistemas de valores, com os nossos códigos sociais e sentimentos de pertencimento, tanto no plano coletivo como individual. Sob o ponto de vista da diversidade cultural, a diversidade linguística reflete a adaptação criativa dos grupos humanos às mudanças no seu ambiente físico e social. Nesse sentido, as línguas não são somente um meio de comunicação, mas representam a própria estrutura das expressões culturais e são portadoras de identidade, valores e concepções de mundo. 
Como se observa, por meio da língua, a diversidade cultural se perpetua, se atualiza e se dinamiza na interação das práticas sociais entre seus próprios nativos eem relação com outras culturas linguísticas. Éa partir da língua que os códigos culturais se traduzem em estruturas de significados que se manifestam mediante a fala, as expressões corporais e artísticas e as variáveis comportamentais.

Partindo do ponto de vista conceitual, conforme defende Tubino Arias-Schreiber (2006, p. 51), a concepção moderna enquanto projeto ideológico não soube reconhecer a alteridade e "se coloca como un proyecto universal descalificando a las culturas no-occidentales como si fueran obstáculos para el progreso tal como nosotros lo hemos concebido". Desse modo, podemos entender que o não-reconhecimento da pluralidade cultural, entre elas, da cultura linguística, coloca em risco a própria diversidade que, "en clave política, se trata de construir ciudadanías diferenciadas en lugar de las clásicas ciudadanías homogéneas" (Tubino Arias-Schreiber, 2006, p. 51).

Essa diversidade de elementos que desenham uma cultura linguística é fundamental para a conformação da identidade, dos valores e das concepções de mundo de cada cultura. Por exemplo, por ocasião da visita de docentes da Universidade de Sevilha à Unesp, vários elementos formais foram confrontados em relação às duas culturas e em relação aos interlocutores da experiência. Alunos e docentes vivenciaram uma oportunidade singular de mediação, relacionamento, interpretação e negociação intercultural, em relação não só à língua, mas também ao comportamento cultural, como requer a metodologia da pesquisa participante: "Escutando e vivenciando, as impressões são formadas e as teorias consideradas, refletidas, desenvolvidas e modificadas" (May, 2004, p. 202).

Para nosso propósito, nessa parceria interuniversitária cabe pensar nas estratégias de comunicação, em especial de relações públicas, não apenas relacionadas aos aspectosdenegociaçãodiretamenteligadosàlínguaespanhola ou portuguesadoBrasil, mas também em relação aos significados mais densos da cultura dos dois países, que exige conhecimento consistente de seus códigos culturais e predisposição ao diálogo. Pode-se admitir que a atividade de relações públicas encontra seu lugar, especialmente, ao considerar a gestão do relacionamento como um processo complexo de concessões, posicionamentos e mediação.

Por último, sobre a identidade das relações públicas, cabe observar a relevância que essa área e o profissional assumem diante do cenário internacional e intercultural. E, ainda, acrescentar a necessidade de manter atenção à formação nesse campo, especialmente, no âmbito do ensino superior. Apesar das diferenças destacadas nos currículos dos cursos das duas universidades e, por conseguinte, do evidente viés pedagógico na formação superior dos estudantes, elas convergiram em um ponto expressivo de negociação de significados entre os participantes, o que os têm induzido à produção de um diálogo permanente sintonizado com as diferentes rotinas universitárias. Todavia, há abordagens epistemológicas distintas entre os cursos, pois enquanto na Espanha a identidade do curso se volta para gestão e promoção de marcas e planos de comunicação com forte viés publicitário, o curso da Unesp busca enfatizar as atividades institucionais e corporativas das organizações.

Contudo, é importante ressaltar que a experiência em relações públicas dos participantes de ambas as universidades foi o ponto de convergência e engajamento para que a parceria pudesse se concretizar. Com isso, reforça-se a identidade das relações públicas na construção de relacionamentos por meio da comunicação bidirecional, a busca da mediação entre os significados de culturas distintas e o foco no equilíbrio de interesses. Numa perspectiva global, o diálogo é essencial e as relações públicas têm, segundo Robert L. Heath (2001, p.36), 
a função de gerenciamento que retoricamente adapta as organizações aos interesses das pessoas e os interesses das pessoas às organizações através da cocriação do significado e do cogerenciamento de culturas para poder alcançar relações de benefício mútuo.

Desse modo, ao mesmo tempo em que essa parceria possibilitou outras experiências, ofereceu a oportunidade de ouvir, observar e refletir sobre outra cultura e sociedade, propiciou diálogos e reuniões presenciais e a distância via web, influenciou na percepção sobre ambas as culturas, criou um sistema particular e conjunto de significados, construiu conhecimentos e aprendizado intercultural, discutiu o ensino-aprendizagem na área, agregou experiências individuais e novos significados, configurando-se numa maneira de aprender com outras culturas e não apenas sobre elas.

\section{CONSIDERAÇÕES FINAIS}

Na prática da observação participante, o papel do pesquisador é organizar os dados coletados a partir da experiência, de modo que eventos, relações e interação observados possam ser entendidos num contexto teórico específico (May, 2004). Sob o paradigma da interculturalidade, com a experiência da parceria internacional de ensino-aprendizagem em relações públicas entre a Unesp e a Universidade de Sevilha, observa-se a importância das relações públicas em um ambiente global, especialmente na promoção do diálogo entre interlocutores de culturas distintas. A partir da vivência intercultural, da negociação de sentidos e significados globais e locais, emergem peculiaridades e acomodações entre pontos de vistas, tanto acadêmicos quanto profissionais.

Neste artigo procurou-se descrever essa vivência ao apresentar algumas questões que emergem do diálogo intercultural. Se a interculturalidade é também interação social, em que há o respeito à diversidade cultural, à convivência e à troca de experiência (Lopes, 2012), também pressupõe um permanente diálogo e ressignificação de visões, valores e pontos de vistas, muitas vezes, contraditórios. Com isso, entende-se que não seria diferente em um ambiente intercultural de ensino-aprendizagem - que pressupõe conflitos - no qual os estudantes possam pensar o sere o fazer relações públicas em circunstâncias desafiadoras. Prepararoestudanteparaumaatuação profissionalamplaeconscienterequerformarcidadãos interculturais, quecompartilhem experiências e adotem posturas profissionais e pessoais para a concretização de uma sociedade mais democrática e justa.

A nossa tese, desde o início dessa parceria, é que a formação em relações públicas para esta nova realidade global exige um olhar intercultural, de modo a se estabelecerem cumplicidades entre os diferentes públicos e culturas, seja potencializando a comunicação corporativa e disseminando informações ou entendendo as características e circunstâncias culturais e estabelecendo diálogos interculturais.

Pode-se dizer que a aprendizagem intercultural fomentada nessa parceria traz ao profissional de relações públicas, para além do conjunto de funções que the são inerentes, pelo menos três aspectos humanizadores, os quais estão diretamente relacionados à interculturalidade. 0 primeiro refere-se à ampliação da capacidade de se colocar no lugar do outro, do diferente, entendendo as distintas narrativas e comportamentos e recriando as relações comunicacionais a partir da diversidade de vínculos sociais. 0 segundo aspecto é a interculturalidade como instrumento de educação, formação humana, permitindo compreender outras ideologias, formas de poder e uma multiplicidade de enredos e discursos, os quais transitam nos distintos cotidianos. E, por fim, o terceiro aspecto relativo à estimulação da função social das relações públicas, pois possibilita ao indivíduo o reconhecimento da realidade que o cerca, não só mediante suas próprias experiências, mas na identificação de elementos, ambientes e pessoas de outras partes do mundo. 


\section{REFERÊNCIAS}

CANDAU, Vera M. F; MOREIRA, Antônio Flávio. Educação escolar e cultura(s): construindo caminhos. Revista Brasileira de Educação, n. 23, p. 156-168, maio/ago. 2003.

LOPES, Ana Maria D'Ávila. Da coexistência à convivência com o outro: entre o multiculturalismo e a interculturalidade. Revista Interdisciplinar da Mobilidade Humana - REMHU, v. 20, n. 38, Brasília, jan./jun. 2012. Disponível em: <http://www.scielo.br/ scielo.php?pid=S1980-85852012000100005\&script=sci_arttext>. Acesso: 23 jun. 2014.

FERRARI, Maria Aparecida. A prática das relações públicas no cenário latino-americano. In: GRUNIG, James E.; FERRARI, Maria Aparecida; FRANÇA, Fábio. Relações públicas: teoria, contexto, relacionamentos. São Caetano do Sul, SP: Difusão, 2009. p. 175-207.

FORNET-BETANCOURT, Raúl. Interculturalidad o barbarie: 11 tesis provisionales para el mejoramiento de las teorías y prácticas de la interculturalidad como alternativa de otra humanidad. Revista Internacional de Comunicación Audiovisual, Publicidad y Estudios Culturales, n. 4, Sevilla (España), 2006, p. 27-49.

HEATH, Robert L. A rhetorical enactment rationale for public relations: the good organization communicating well. In: HEATH, Robert L. (Ed). Handbook of public relations. London: Sage, 2001. p. 31-50.

MAY, Tim. Pesquisa social: questões, métodos e processos. Porto Alegre: Artmed, 2004.

PEÑAMARÍN, Cristina. Malentendido intercultural e intracultural. Revista Internacional de Comunicación Audiovisual, Publicidad y Estudios Culturales, n. 4, Sevilla (España), 2006, p. 141-155.

PERUZZO, Cicilia M. Krohling. Observação participante e pesquisa-ação. In: DUARTE, Jorge; BARROS, Antônio (Org.). Métodose técnicas de pesquisa em comunicação. São Paulo: Atlas, 2005. p. 125-145.

SANTOS, Boaventura de Sousa (Org.). A gramática do tempo: para uma nova cultura política. São Paulo: Cortez, 2006.

TUBINO ARIAS-SCHREIBER, Fidel. En nombre de la lengua perfecta. Revista Internacional de Comunicación Audiovisual, Publicidad y Estudios Culturales, n. 4, Sevilla (España), 2006, p. 51-64.

UNESCO. Relatório Mundial sobre a Diversidade Cultural. In: UNESCO. Investir na diversidade cultural e no diálogo intercultural. 2009. Disponível em: <http://unesdoc.unesco.org/images/0018/001847/184755por.pdf>. Acesso em: 22 ago. 2012.

WALSH, Catherine (Org.). Pensamiento crítico y matriz (de)colonial: reflexiones latinoamericanas. Quito: Universidad Andina Simón Bolivar / Abya-Yala, 2005. 